\title{
Novel uncultivated labyrinthulomycetes revealed by 18S rDNA sequences from seawater and sediment samples
}

\author{
Enixy Collado-Mercado, JoAnn C. Radway, Jackie L. Collier* \\ School of Marine and Atmospheric Sciences, Stony Brook University, Stony Brook, New York 11794-5000, USA
}

\begin{abstract}
Labyrinthulomycetes (Labyrinthulea) are ubiquitous marine osmoheterotrophic protists that appear to be important in decomposition of both allochthonous and autochthonous organic matter. We used a cultivation-independent method based on the labyrinthulomycete-specific primer LABY-Y to PCR amplify, clone, and sequence 68 nearly full-length 18S rDNA amplicons from 4 sediment and 3 seawater samples collected in estuarine habitats around Long Island, New York, USA. Phylogenetic analyses revealed that all 68 amplicons belonged to the Labyrinthulea. Only 15 of the 68 amplicons belonged to the thraustochytrid phylogenetic group (Thraustochytriidae). None of these 15 were similar to cultivated strains, and 11 formed a novel group. The remaining 53 amplicons belonged either to the labyrinthulid phylogenetic group (Labyrinthulidae) or to other families of Labyrinthulea that have not yet been described. Of these amplicons, 37 were closely related to previously cultivated Aplanochytrium spp. and Oblongichytrium spp. Members of these 2 genera were also cultivated from 1 of the sediment samples. The 16 other amplicons were not closely related to cultivated strains, and 15 belonged to 5 groups of apparently novel labyrinthulomycetes. Most of the novel groups of amplicons also contained environmental sequences from surveys of protist diversity using universal 18S rDNA primers. Because the primer LABY-Y is biased against several groups of labyrinthulomycetes, particularly among the thraustochytrids, these results may underestimate the undiscovered diversity of labyrinthulomycetes.
\end{abstract}

KEY WORDS: Aplanochytrid - Labyrinthulid - Thraustochytrid - Small subunit ribosomal RNA · SSU rRNA

\section{INTRODUCTION}

Labyrinthulomycetes are abundant and widespread osmoheterotrophic marine protists that appear likely to play an important, fungus-like role in the mineralization of organic matter in the oceans (for a review, see Raghukumar 2002). Labyrinthulomycetes are characterized by the production of an ectoplasmic network, comprising extensions of the plasma membrane that provide intimate physical and nutritional connection with the substrate. They can degrade a wide variety of biopolymers including some highly refractory substrates such as sporopollenin. Labyrinthulomycetes appear to have fairly simple and predominantly asex- ual life cycles, including a motile (either by typical heterokont flagellae or by gliding) zoospore stage. The cell wall is made of overlapping thin scales of protein and sulfated polysaccharides. While some species have gained notice as pathogens of marine plants and invertebrates (e.g. Bower 1987, Muehlstein et al. 1988, Whyte et al. 1994), most are believed to be either freeliving or commensal saprobes.

The classification of labyrinthulomycetes is still in flux, with 3 different but parallel systems proposed in which the group is ranked as a phylum (Labyrinthulomycota or Labyrinthulomorpha), class (Labyrinthulea or Labyrinthista), or order (Labyrinthulida) within the heterokonts (Porter 1990, Cavalier-Smith et al. 1994, 
Dick 2001, Cavalier-Smith \& Chao 2006). Whatever name and rank the labyrinthulomycetes are given, they are usually divided into 2 subgroups, such as the families Labyrinthulidae (or Labyrinthulaceae) and Thraustochytriidae (or Thraustochytriaceae), or the orders Labyrinthulales and Thraustochytriales. Molecular genetic analyses generally support the existence of a monophyletic group within the labyrinthulomycetes that was called the thraustochytrid phylogenetic group by Honda et al. (1999) and includes many species assigned to the Thraustochytriidae. It is less clear whether there is a monophyletic labyrinthulid phylogenetic group corresponding to the Labyrinthulidae, and it has been proposed that the aplanochytrids comprise a third group of labyrinthulomycetes distinct from the labyrinthulids and thraustochytrids (Leander \& Porter 2000, 2001, Leander et al. 2004). The naming and assignment of cultivated isolates to phylogenetically coherent genera has been difficult because of the paucity of morphological features and their variability with growth conditions. Several recent studies have advanced the process of making genus- and higherlevel classification of these organisms consistent with their morphology, biochemistry, and molecular genetic relationships (e.g. Yokoyama \& Honda 2007, Yokoyama et al. 2007, Tsui et al. 2009).

Most of what is known about the diversity and distribution of labyrinthulomycetes is derived from cultivation-dependent approaches, especially using a pine pollen baiting method. Raghukumar (2002) concluded that members of the genera Labyrinthula and Aplanochytrium are often associated with living plants and algae, either as parasites or commensals, while thraustochytrids may be more sensitive to the antimicrobial compounds produced by living plant substrates and more commonly found on plant and algal detritus. Labyrinthula has never been reported from open waters, but Aplanochytrium is abundant in the Indian Ocean (Damare \& Raghukumar 2006). In addition to normoxic habitats, labyrinthulomycetes have been observed in and cultivated from suboxic and sulfiderich water column and sediment habitats, and have even been cultivated anaerobically under a nitrogen atmosphere (Goldstein 1973, Riemann \& Schrage 1983, Raghukumar et al. 2001). The abundance of labyrinthulomycetes has been estimated to reach up to 100000 cells kg-1 in sediments and up to 1000000 cells $\mathrm{l}^{-1}$ in the water column (Raghukumar 2002).

Labyrinthulomycete sequences have been detected in many of the recent cultivation-independent surveys of marine protist diversity using 'universal' eukaryotic 18S rDNA primers, including in typical water column samples (Massana et al. 2004a,b, Not et al. 2007), anoxic Cariaco Basin and anoxic fjord water column samples (Stoeck et al. 2003, 2006, Behnke et al. 2006, Zuendorf et al. 2006), and sediment samples (Edgcomb et al. 2002, Stoeck et al. 2007). In the present study we took a more direct cultivation-independent approach to investigate the diversity of labyrinthulomycetes by using the LABY-Y primer, which was developed by Stokes et al. (2002) to provide broad recognition of labyrinthulomycete $18 \mathrm{~S}$ rDNA. We used phylogenetic analyses to compare the diversity revealed by cultivation-independent approaches with the diversity of labyrinthulomycetes known from cultivated strains, and found at least 10 novel groups of labyrinthulomycetes that were not closely related (<95\% identical $18 \mathrm{~S}$ rDNA sequences) to cultured isolates.

\section{MATERIALS AND METHODS}

Environmental sample collection and DNA purification. Sediment and seawater samples were collected from 4 sites around Long Island, New York, USA (Table 1). A Ponar type grab sampler $\left(0.04 \mathrm{~m}^{2}\right)$ was used to collect sediment, and sediment type was characterized visually by color and grain size. The top $2 \mathrm{~cm}$ of sediment were scraped into a clean container, mixed, divided into approximately $2 \mathrm{~g}$ (wet weight) subsamples by filling sterile $2.0 \mathrm{ml}$ Nalgene cryovials (Thermo Fisher Scientific), and stored on wet or dry ice until returned to the lab and then stored at $-70^{\circ} \mathrm{C}$ until DNA extraction. Water column samples were collected

Table 1. Sample collection sites and characteristics

\begin{tabular}{|llcccc|}
\hline $\begin{array}{l}\text { Sample designation } \\
\text { (No. of clones) }\end{array}$ & Collection site & Location & Date & $\begin{array}{c}\text { Bottom } \\
\text { depth }\end{array}$ & Comments \\
\hline PJS101305 (27) & Port Jefferson Harbor & $40^{\circ} 57^{\prime} \mathrm{N}, 73^{\circ} 05^{\prime} \mathrm{W}$ & 13 Oct 2005 & $12 \mathrm{~m}$ & Sandy sediments \\
PBS102405 (14) & Peconic Bay & $40^{\circ} 56^{\prime} \mathrm{N}, 72^{\circ} 30^{\prime} \mathrm{W}$ & 24 Oct 2005 & $12 \mathrm{~m}$ & Muddy, green sediments \\
PBS102907 (5) & Peconic Bay & $40^{\circ} 56^{\prime} \mathrm{N}, 72^{\circ} 30^{\prime} \mathrm{W}$ & 29 Oct 2007 & $12 \mathrm{~m}$ & Muddy, green sediments \\
PBW102907 (1) & Peconic Bay & $40^{\circ} 56^{\prime} \mathrm{N}, 72^{\circ} 30^{\prime} \mathrm{W}$ & 29 Oct 2007 & $12 \mathrm{~m}$ & Well-mixed water column \\
LISS100206 (5) & Long Island Sound & $41^{\circ} 04^{\prime} \mathrm{N}, 73^{\circ} 08^{\prime} \mathrm{W}$ & 2 Oct 2006 & $20 \mathrm{~m}$ & Muddy sediment \\
LISW100206 (1) & Long Island Sound & $41^{\circ} 04^{\prime} \mathrm{N}, 73^{\circ} 08^{\prime} \mathrm{W}$ & 2 Oct 2006 & $20 \mathrm{~m}$ & Surface mixed layer \\
BBW042908 (5) & Bowery Bay & $40^{\circ} 47^{\prime} \mathrm{N}, 73^{\circ} 53^{\prime} \mathrm{W}$ & 29 Apr 2008 & $10 \mathrm{~m}$ & Well-mixed water column \\
\hline
\end{tabular}


with a General Oceanics 21 Niskin bottle, and particulate matter was collected from $100 \mathrm{ml}$ subsamples onto $45 \mathrm{~mm}$ diameter polycarbonate filter membranes with pore sizes of $1 \mu \mathrm{m}$ (PBW102907) or $20 \mu \mathrm{m}$ (LISW100206 and BBW042908). The filters were stored on wet or dry ice until returned to the lab and then stored at $-70^{\circ} \mathrm{C}$ until DNA extraction.

DNA was extracted from sediment samples using the FastDNA SPIN Kit for Soil (MP Biomedicals). For sandy samples, $500 \mathrm{mg}$ were placed in a Lysing Matrix E tube and homogenized for 12 min using a Vortex Genie 2 with a TurboMix attachment (Scientific Industries), whereas for muddy samples $450 \mathrm{mg}$ were homogenized for $15 \mathrm{~min}$. After this point the manufacturer's instructions were followed. All DNA extracts were treated with the Wizard DNA Clean-Up System (Promega) to reduce PCR inhibition. The integrity and quantity of total community DNA was checked by agarose gel electrophoresis.

DNA was extracted from the Long Island Sound water sample (LISW100206) by a modification of the potassium ethyl xanthogenate protocol of Tillett \& Neilan (2000) as described previously (Baker et al. 2009). Because this template proved very difficult to amplify, DNA was extracted from the Peconic Bay and Bowery Bay water samples (PBW102907 and BBW042908) by a modification of the protocol of Countway et al. (2005). Briefly, filters that had been stored frozen in $2 \mathrm{ml}$ lysis buffer (100 mM Tris pH 8, 40 mM EDTA pH 8, 100 mM $\mathrm{NaCl}, 1 \%$ sodium dodecyl sulfate) were thawed, and $100 \mu \mathrm{l}$ of TER buffer (TE $\mathrm{pH} 8$ plus $15 \mathrm{mg} \mathrm{ml}^{-1}$ RNase A), $2 \mu \mathrm{l}$ of Proteinase $\mathrm{K}\left(10 \mathrm{mg} \mathrm{ml}^{-1}\right)$, and $200 \mu \mathrm{l}$ of $0.5 \mathrm{~mm}$ zircon beads (BioSpec Products) were added per filter. The filters were subjected to 3 rounds of vortexing for $30 \mathrm{~s}$ and heating in a water bath at $70^{\circ} \mathrm{C}$ for $5 \mathrm{~min}$. Samples rested in ice for $30 \mathrm{~min}$ before the filter was removed by squeezing the lysate through a $10 \mathrm{ml}$ syringe. Each sample was then centrifuged at $10000 \times g$ (10 min) and the supernatant was divided into several $1.7 \mathrm{ml}$ tubes. One $\mu \mathrm{l}$ of glycogen (Sigma-Aldrich) was added to each tube, and DNA was precipitated with 1 volume of $95 \%$ ethanol and 0.1 volume of $10.5 \mathrm{M}$ am- monium acetate overnight at $-20^{\circ} \mathrm{C}$. The precipitated DNA was collected by centrifugation at $16000 \times g$ and the pellet was rinsed with $70 \%$ ethanol, air dried, and dissolved in $50 \mu$ l distilled deionized water $\left(\mathrm{ddH}_{2} \mathrm{O}\right)$. DNA extracts were cleaned with the Promega Wizard DNA Clean-Up System and checked by agarose gel electrophoresis.

PCR amplification, cloning, and sequencing of environmental amplicons. DNA from each sample was used as template in $\mathrm{PCR}$ reactions with the primer pairs LABY-A and LABY-Y ( 450 bp product), QPX-F and QPX-R2 ( 650 bp product), 18S-F and LABY-Y ( 1400 bp product), and 18S-F and 18S-R ( 1800 bp product). Primer sequences, sources, and locations in 18S rDNA are shown in Table 2. To ensure that lack of amplification was not due to any technical problems or PCR inhibition, parallel positive control reactions containing DNA from lab-grown QPX cells (Qian et al. 2007) were also run with and without each environmental DNA template. In addition to controls for contamination to which no template DNA was added, controls for amplification specificity were run with genomic DNA from Rhodomonas lens CCMP739 or Thalassiosira weissflogii CCMP1336. The primers were commercially synthesized by Integrated DNA Technologies (Coralville, Iowa, USA). Fifty $\mu$ l (total volume) PCR reactions were made with Promega reagents as follows: $5 \mu \mathrm{l}$ each $1 \mathrm{mM} \mathrm{MgCl}, 10 \times$ buffer, $2 \mathrm{mM}$ dNTPs and $1 \mu \mathrm{M}$ each primer; $2.5 \mu \mathrm{l} \mathrm{DMSO} ;$ $20.5 \mu \mathrm{lddH_{2 }}$ O; $0.5 \mu \mathrm{l}$ Taq polymerase; and $1.5 \mu \mathrm{l} \mathrm{tem-}$ plate DNA. The PCR program was 35 cycles of $94^{\circ} \mathrm{C}$ for $30 \mathrm{~s}, 50^{\circ} \mathrm{C}$ for $1 \mathrm{~min}$, and $72^{\circ} \mathrm{C}$ for $2 \mathrm{~min}$, followed by a final extension at $72^{\circ} \mathrm{C}$ for $10 \mathrm{~min}$. Reaction products were examined by agarose gel electrophoresis. If only a weak band of the expected size was found, yield was increased by running an additional 15 cycles after adding $0.5 \mu \mathrm{l}$ Taq polymerase, $0.5 \mu \mathrm{l} 10 \times$ buffer, $0.3 \mu \mathrm{l}$ $\mathrm{MgCl}_{2}, 0.5 \mu \mathrm{ldNTPs}$, and $0.2 \mu \mathrm{LMSO}$ to the original reaction.

PCR products were cleaned with the StrataPrep PCR Purification Kit (Stratagene), and clone libraries were constructed by following the instructions for Promega's

Table 2. Primers used in the present study. 'Position' refers to the position in the AF261664 QPX sequence

\begin{tabular}{|c|c|c|c|}
\hline Name & Sequence $\left(5^{\prime}\right.$ to $\left.3^{\prime}\right)$ & Position & Source \\
\hline $18 \mathrm{~S}-\mathrm{F}^{\mathrm{a}}$ & AAC CTG GTT GAT CCT GCC AGT & 1 to 21 & Medlin et al. 1988 \\
\hline QPX-F & ATC CTC GGC CTG CTT TTA GTA G & 695 to 716 & Stokes et al. 2002 \\
\hline LABY-A & GGG ATC GAA GAT GAT TAG & 964 to 981 & Stokes et al. 2002 \\
\hline LABY-Arev & CTA ATC ATC TTC GAT CCC & 964 to 981 & The present study \\
\hline QPX-R2 & GAA GTC TCT ACC TTT CTT GCG A & 1338 to 1359 & Stokes et al. 2002 \\
\hline LABY-Y & CWC RAA CTT CCT TCC GGT & 1381 to 1398 & Stokes et al. 2002 \\
\hline $18 \mathrm{~S}-\mathrm{R}^{\mathrm{b}}$ & TGA TCC TTC TGC AGG TTC ACC TAC & 1766 to 1789 & Medlin et al. 1988 \\
\hline
\end{tabular}


pGEM-T Easy Kit. Plasmid DNA was purified from presumed positive (white) colonies according to Promega's Wizard Miniprep Kit, and the presence of an insert of the appropriate size was confirmed by restriction digestion with EcoRI and agarose gel electrophoresis. Cloned amplicons were sequenced completely on both strands using ABI (PE Biosystems) reagents and an ABI3130XL sequencer.

Cultivation and sequencing of new labyrinthulomycete isolates. Three subsamples from sediment sample PBS102907 were diluted sufficiently to allow pipetting, and a 10-fold dilution series was prepared from each using $0.2 \mu \mathrm{m}$ filtered surface seawater. Aliquots $(100 \mu \mathrm{l})$ of $10 \times, 100 \times$, and $1000 \times$ dilutions were spread in triplicate on modified ATCC $790 \mathrm{By}+$ plates containing (per liter of filtered seawater) $1 \mathrm{~g}$ yeast extract, $1 \mathrm{~g}$ peptone, $5 \mathrm{~g}$ D-glucose, $10 \mathrm{ml} 100 \times$ MEM vitamins (Sigma-Aldrich), $12 \mathrm{~g}$ agar and $10 \mathrm{ml}$ penicillin/streptomycin mix (10000 units $\mathrm{ml}^{-1}$ and $10 \mathrm{mg} \mathrm{ml}^{-1}$ respectively; Sigma-Aldrich). Plates were incubated at $22^{\circ} \mathrm{C}$ and colonies were picked into liquid $790 \mathrm{By}+$ medium. Some isolates were later found to grow better on horse serum medium (HS) containing (per liter of filtered seawater) $20 \mathrm{ml}$ horse serum, $12 \mathrm{~g}$ agar, 100000 units penicillin, and $100 \mathrm{mg}$ streptomycin.

DNA was extracted from cultivated strains using the Qiagen DNEasy Tissue Kit with an overnight lysis step, and the 18S rDNA was amplified using primers $18 \mathrm{~S}-\mathrm{F}$ and 18S-R (Table 2). After treatment with ExoSAP-It $(1 \mu \mathrm{l}$ per $10 \mu \mathrm{l}$ PCR product; USB), the PCR products were quantified (Quant-iT PicoGreen dsDNA Kit; Invitrogen) and directly sequenced using primers $18 \mathrm{~S}-\mathrm{F}$, 18S-R, LABY-A, LABY-Y, and LABY-Arev (Table 2). Sequencing was performed using 20 to $30 \mathrm{ng}$ PCR product per reaction, $\mathrm{ABI}$ reagents, and an ABI3130XL sequencer.

Phylogenetic analyses. Sequencing chromatograms were edited and amplicon sequences were assembled manually using BioEdit (Hall 1999). The environmental 18S-F/LABY-Y amplicon sequences described here were submitted to GenBank under accession numbers FJ800585 to FJ800652, and the cultivated strain 18S rDNA sequences were submitted to GenBank under accession numbers FJ799794 to FJ799799 and GQ354272. As a first check of their phylogenetic affiliation, all sequences were subjected to BLAST searches against GenBank. To identify possible chimeras, each sequence was divided into fragments 350 to $400 \mathrm{bp}$ in length, and the best BLAST hits for each fragment were compared; no clear chimeras were found this way. Chimera_Check at Ribosomal Database Project II and Bellerophon (Huber et al. 2004) were also used to search for chimeric amplicons. The potential chimeras identified by Bellerophon were all within the Apla- nochytrium and Oblongichytrium groups and were similar to sequences from cultivated labyrinthulomycetes and from multiple different environmental samples, so they were considered unlikely to be real chimeras and were not excluded from the analysis.

The 68 environmental 18S-F/LABY-Y amplicon sequences and $718 \mathrm{~S}$ rDNA sequences from strains cultivated during this study, plus 214 sequences from previously cultivated labyrinthulomycetes and 50 likely labyrinthulomycete environmental sequences from other studies identified in GenBank (last searched in June 2009), were aligned manually in BioEdit with a structure-based 18S rDNA alignment (Wuyts et al. 2004) containing 264 representative sequences from fungi, plants, alveolates, and the major groups of heterokonts as outgroups. Some environmental sequences that were originally reported as representing labyrinthulomycetes were excluded because they appear to be chimeras (AY046667 and AY046602 of Edgcomb et al. 2002; AY916573 of Luo et al. 2005) or appear to have been associated with the Labyrinthulea in some analyses because of branch length artifacts but to really represent other taxa (AF290070 of LópezGarcía et al. 2001 belongs to MAST-V of Massana et al. 2004b; AY821979 of Slapeta et al. 2005 and its relatives were not identified as labyrinthulomycetes in the studies of Edgcomb et al. 2002, Amaral Zettler et al. 2002, or Richards et al. 2005). Initial neighbor-joining phylogenetic trees were constructed with MEGA 3.1 (Kumar et al. 2004) using the Tamura 3-parameter model with pairwise deletion, unequal rates among lineages, gamma equal to 0.5 or 1 , and 100 bootstrap replications. To enable analysis by the maximum likelihood method implemented in MrBayes 3.1 (Ronquist \& Huelsenbeck 2003), a smaller alignment was made by retaining a reduced set of sequences from the outgroups and only 1 or a few sequences to represent groups of cultivated labyrinthulomycetes with almost identical sequences. This alignment, containing 149 outgroup sequences and 165 previously cultivated labyrinthulomycete sequences (434 sequences total), was also analyzed by neighbor-joining and 'Randomized Axelerated Maximum Likelihood' (RAxML; Stamatakis et al. 2008). To facilitate presentation of the phylogenetic analyses, 41 sequences that were nearly identical to others were removed from the 434 sequence alignment, and the tree produced by RAxML from the resulting 393 sequence alignment is presented in Fig. 1. Because some sequences did not cover the entire 18S rDNA gene, many positions in the 434 sequence alignment were missing in some sequences. Two additional alignments were constructed for analyses based only on common sequenced regions for subsets of the data. In the 425 taxon alignment, 9 cultivated labyrinthulomycete and environmental 


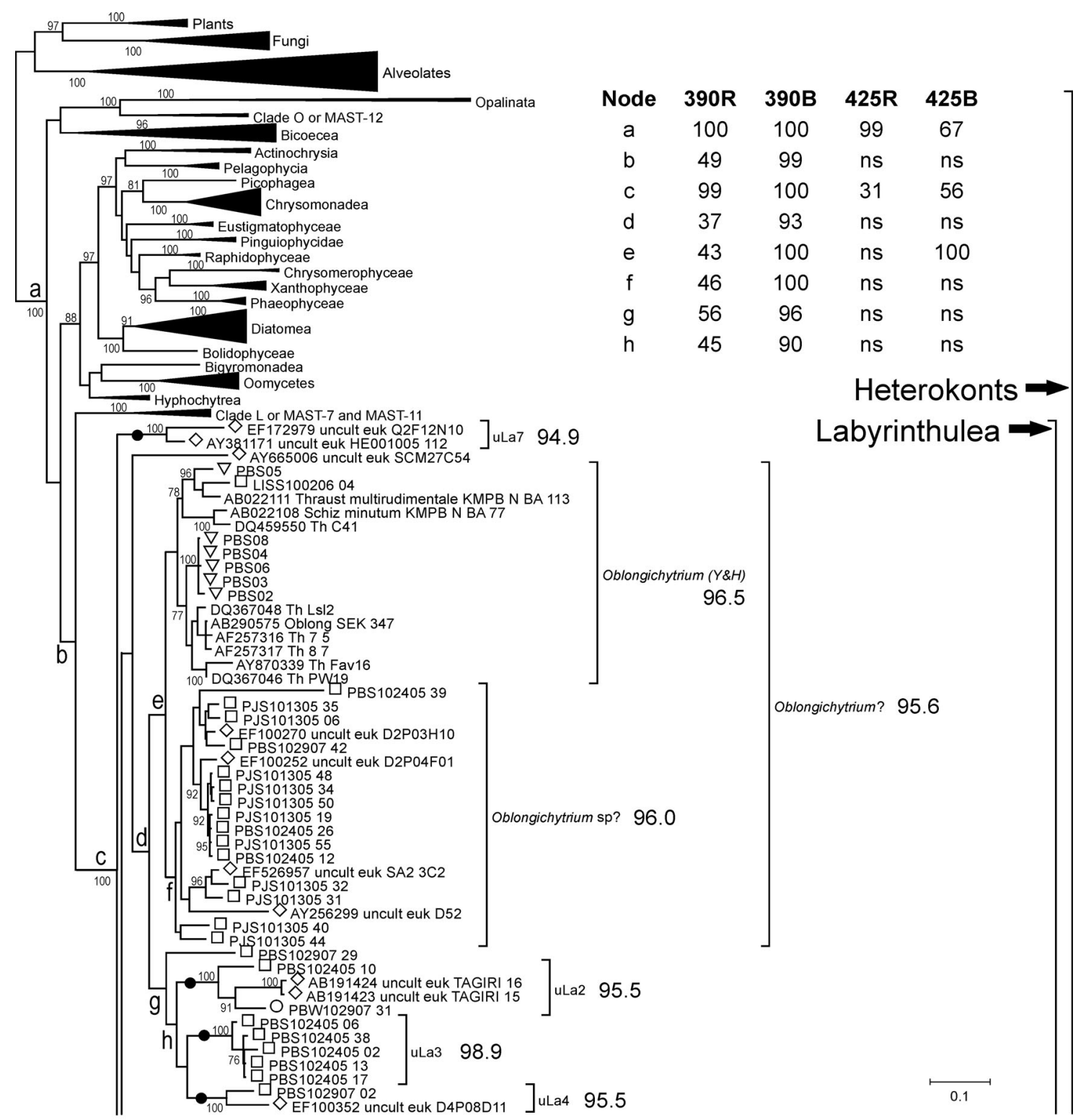

Fig. 1 (continued overleaf). Representative phylogenetic tree from RAxML analysis of a 393 taxon alignment. Taxonomic groups outside the labyrinthulomycetes were identified following Cavalier-Smith \& Chao (2006). ( $\square$ ) 18S-F/LABY-Y amplicons from sediment samples; $(O)$ water column samples; and $(\diamond)$ environmental amplicons (uncultured eukaryote sequences, uncult euk) from other studies. The 7 isolates from the present study are indicated with $(\nabla)$. Numbers near the name of each group of similar sequences are the average percent identity for the sequences in that group. Abbreviations of species names: Aplan, Aplanochytrium; Aurant, Aurantiochytrium; Botry, Botryochytrium; Japon, Japonochytrium; La, Labyrinthula; Loides, Labyrinthuloides; Oblong, Oblongichytrium; Pariet, Parietichytrium; Schiz, Schizochytrium; Sicyoid, Sicyoidochytrium; Th, Thraustochytriidae; Thraust, Thraustochytrium. Values at nodes are RAxML bootstrap support for this tree; only values $>75 \%$ are shown. The tables show the statistical support from other analyses for the specific nodes indicated: 390R and 390B, bootstrap and posterior probability $\left({ }^{*} 100\right)$ support from RAxML and MrBayes analyses (respectively) of the 390 taxon alignment covering the 18S-F to LABY-Y region; 425R and 425B, bootstrap and posterior probability ( $\left.{ }^{*} 100\right)$ support from RAxML and MrBayes analyses (respectively) of the 425 taxon alignment covering only the region of AB219774; ns indicates that a node was not supported. (•) Nodes had at least $90 \%$ bootstrap support or posterior probability $>0.9$ in all analyses. In addition to the sequences shown in this figure, in analyses with the full alignment Aplanochytrium includes EU851168, EU851169, EU851170, AF265339, AY046604, AY046781, DQ103777, DQ103805; Labyrinthula includes CL603045-CL603052, CL603054, AB290455, AB290457, AB290459, AB246795, EU431330, AY426935; Oblongichytrium includes DQ367047; Aurantiochytrium includes AB183660, AB183662, AB002107, AB290572, AY705741, AY705744-AY705750, AY705757-AY705762, AY705764-AY705768, AY705770, AY705771, AY705773, AY705775-AY705777, AY705783, AY773276, DQ023611-DQ023613，DQ023616，DQ023618-DQ023621，DQ160193，DQ836628，DQ836631; Ulkenia (sensu stricto) includes AB290335, DQ100296, L34054; Schizochytrium (sensu stricto) includes AB290577, AB290354, AB290576, DQ023617; Thraustochytrium gaertnerium includes AY705754, AY705756; Thraustochytrium kinnei includes DQ459552; Botryochytrium includes AB022115; Parietichytrium includes AB290352, AB290353; Sicyoidochytrium includes AB183653, AB183654; Thraustochytrium caudivorum includes EF114347-EF114353, EF114355; and Thraustochytriidae BS1 groups with AF257315 (BS2). Scale bar shows substitutions per nucleotide site 


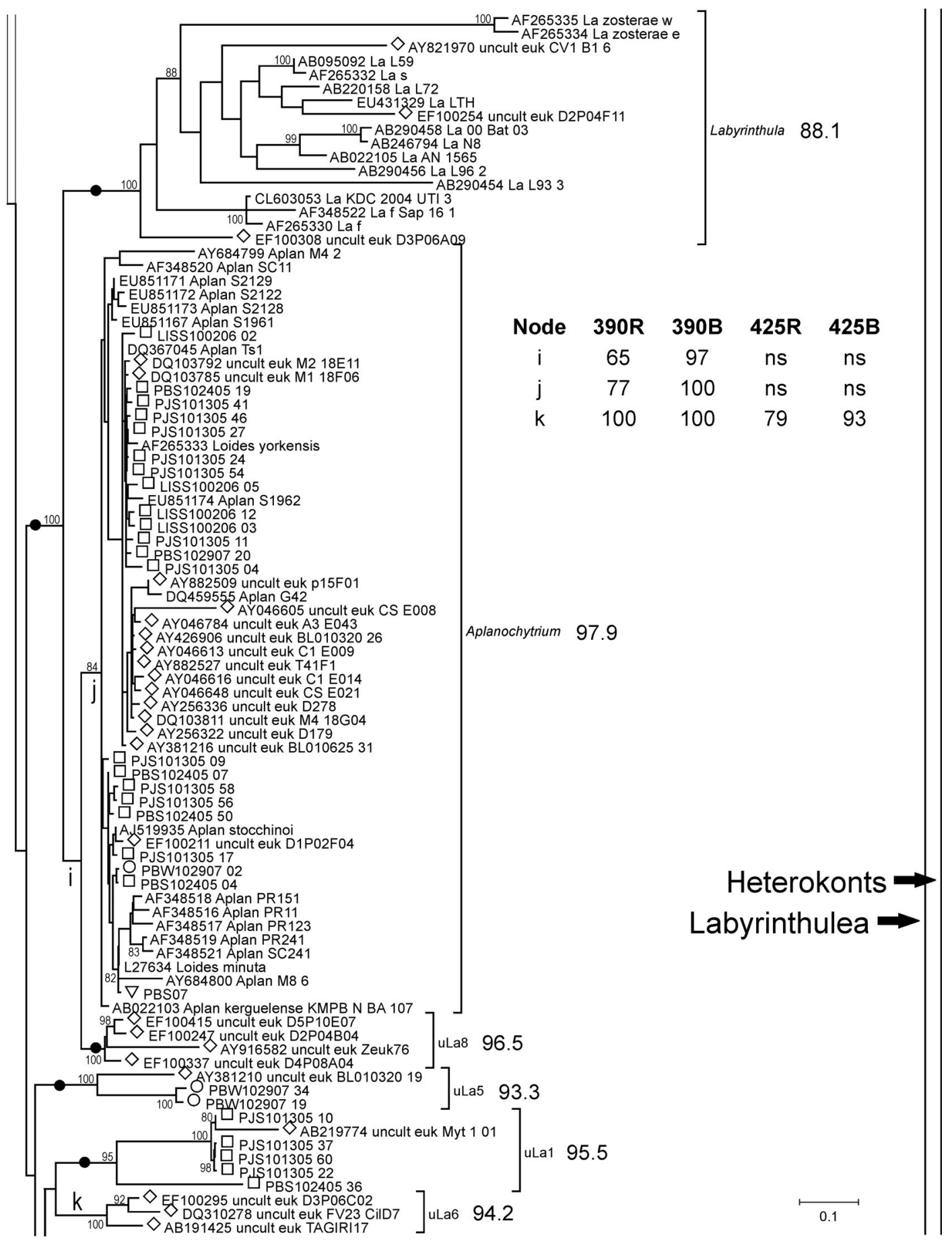

Fig. 1 (continued)

sequences that did not cover the entire 588 bp of environmental sequence AB219774 were removed, providing 555 characters for analysis after exclusion of ambiguous positions. In the 390 taxon alignment, 35 additional cultivated labyrinthulomycete and environmental sequences that did not include the entire 18S-F to LABY-Y region were removed, providing 1269 characters for analysis after exclusion of ambiguous positions. Phylogenetic analyses on the 425 and 390 taxon alignments were performed using RAxML and MrBayes, and the support provided by these analyses for various groups of sequences is shown in Fig. 1. 


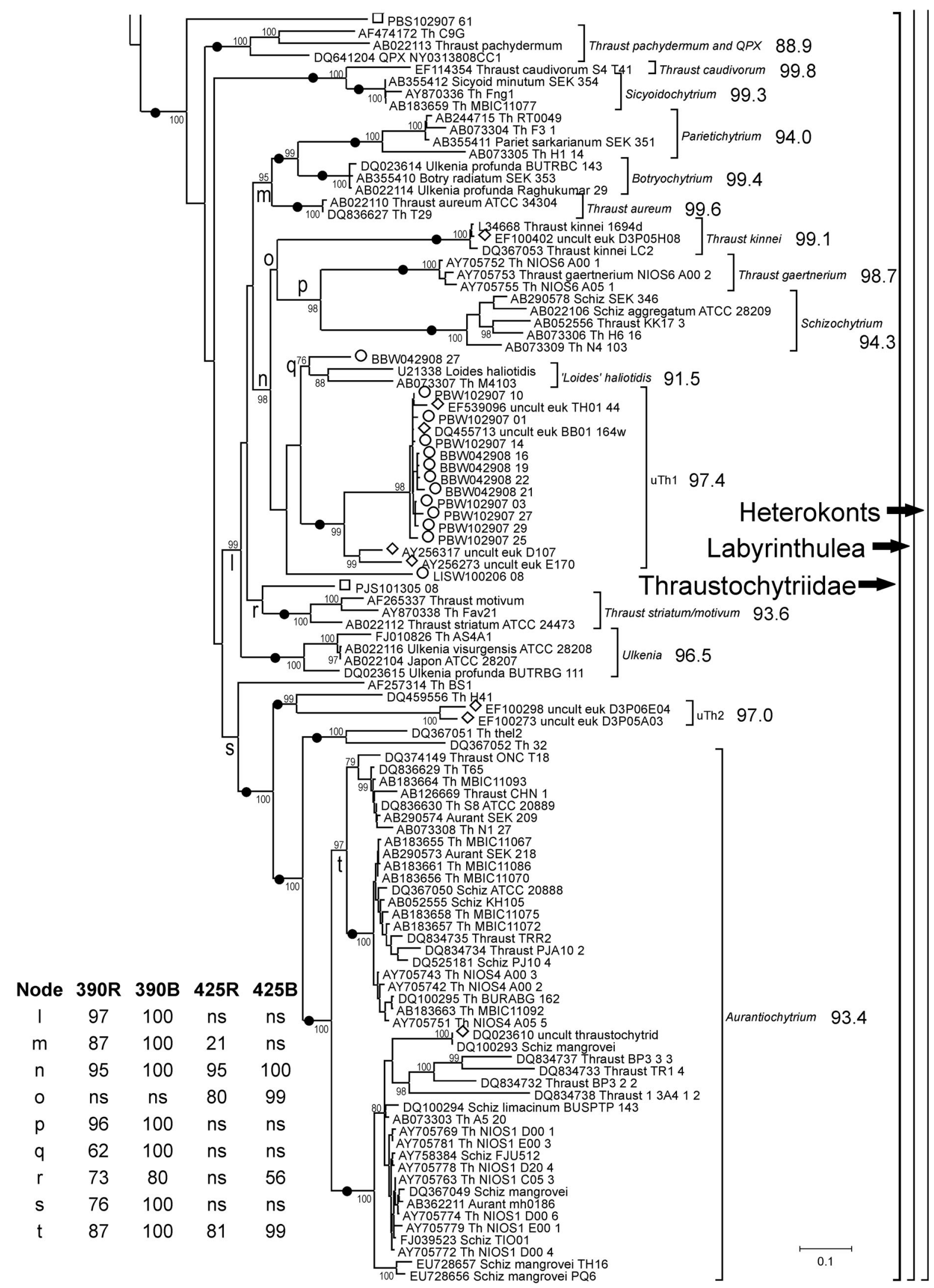

Fig. 1 (continued) 


\section{RESULTS}

Stokes et al. (2002) designed 1 set of primers, QPX-F and QPX-R2, intended to be specific to the thraustochytrid QPX, along with a set of primers, LABY-A and LABY-Y, that recognized a broader range of labyrinthulomycetes (Table 2). Comparison of QPX-F and QPX-R2 against the GenBank database by BLAST (last searched in June 2009) confirmed that only $18 \mathrm{~S}$ rDNA sequences from QPX perfectly matched each of these primers (data not shown). The QPX-F/QPX-R2 primer pair reliably amplified the expected product ( 650 bp) from QPX control DNA but not from Rhodomonas lens CCMP739 or Thalassiosira weissflogii CCMP1336 control DNA or from any of the environmental DNA templates. In contrast, the universal eukaryote primer pair 18S-F/18S-R (Table 2; primers modified from Medlin et al. 1988) reliably amplified the expected product $(\sim 1800 \mathrm{bp})$ from QPX, $R$. lens CCMP739, and T. weissflogii CCMP1336, as well as from environmental DNA templates. Comparison of LABY-Y with the GenBank database revealed that LABY-Y was specific to labyrinthulomycetes in that it perfectly matched many labyrinthulomycete $18 \mathrm{~S}$ rDNA sequences but not those of any other eukaryotes, although it did not perfectly match all labyrinthulomycetes (Fig. 2, Table 3). LABY-A was more general, perfectly matching almost all labyrinthulomycete $18 \mathrm{~S}$ rDNA sequences but also those of many other eukaryotes (mostly other heterokonts; Table 3 ). The primer pair LABY-A/LABY-Y reliably amplified the expected product from QPX DNA but not from $R$. lens CCMP739 or T. weissflogii CCMP1336 DNA, and produced an amplicon of the expected size from all environmental DNA templates tested. We sequenced 38 LABY-A/

LABY-Y (reverse complement)
Aplanochytrium
Labyrinthula
oblongichytrium
Sicyoidochytrium
Ulkenia(sensu stricto)
Parietichytrium
Botryochytrium
Thraustochytrium NIOS-6
Thraustochytrium caudivorum
Thraustochytriidae BS1, BS2
Schizochytrium (sensu stricto)
Aurantiochytrium
Thraustochytriidae NIos-1 type
Thraustochytriidae NIos-4 type
Schizochytrium limacinum
Schizochytrium mangrovei

ACCGG-AAGGAAGTTYGWG ACCGG-AAGGAAGTTTGWG ACYGR-AAGGAAGTTYGWG ACCGG-AAGGAAGTTYGWG ACCGG-AAGGAAGTTYGWG ACCGG-AAGGAAGTTYGWG ACCGG-AAGGAAGTTYGWG ACCGG-AAGGAAGTTYGWG ACTGG-AAGGAAGTTYGWG ACCGG-AAGGAAGTGYGWG ACCGG-ATGGAAGTTYGWG ACCAG-AGGGAAGTTYGWG

ACGGG-CAGGAAGTTYGAG ACGAG-CAGGAAGTTYGAG AC-GG-CAGGA-GTTY-AG ACCGAGAAGGAAGTTYGAG
Fig. 2. Consensus LABY-Y primer binding site in major groups of labyrinthulomycetes. The $18 \mathrm{~S}$ rDNA sequences are from $5^{\prime}$ to $3^{\prime}$; for ease of comparison, the reverse complement of LABY-Y is shown in the first line. Degeneracy coding: $\mathrm{Y}=\mathrm{C}$ or $\mathrm{T}, \mathrm{R}=\mathrm{A}$ or $\mathrm{G}, \mathrm{W}=\mathrm{A}$ or $\mathrm{T}$
LABY-Y cloned amplicons from the PJS101305 template and 37 from the PBS102405 template. These amplicons were most similar to either cultured labyrinthulomycete or environmental 18S rDNA sequences in BLAST searches of GenBank, and generally grouped with labyrinthulomycetes in phylogenetic analyses, but were too short ( 450 bp) to give robust statistical support (data not shown). To obtain longer, more phylogenetically informative labyrinthulomycete $18 \mathrm{~S}$ rDNA sequences from environmental samples, LABY-Y was paired with 18S-F (Tables 2 \& 3). Like LABY-A/LABY-Y, the 18S-F/LABY-Y primer pair reliably amplified the expected product $(\sim 1400 \mathrm{bp})$ from QPX DNA but not from $R$. lens CCMP739 or $T$. weissflogii CCMP1336 DNA. 18S-F/LABY-Y also amplified the expected product from environmental DNA templates, although extra cycles were often required to generate enough for cloning.

In total, 68 18S-F/LABY-Y amplicons were cloned and sequenced from 4 sediment and 3 seawater samples collected around Long Island (Table 1). In BLAST analyses against GenBank, the 18S-F/LABY-Y amplicons were most similar to either cultured labyrinthulomycete or environmental 18S rDNA sequences (data not shown). The results of many different phylogenetic analyses, using different taxon sets, regions of 18S rDNA sequence, and methods, were largely consistent with each other. Fig. 1 shows the topology of a phylogenetic tree constructed by RAxML from a 393 taxon alignment (see 'Materials and methods'). Differences between this and other trees were mainly in the strength of statistical support (bootstrap or posterior probability); in particular, the analyses with the fewest characters (using the 425 taxon alignment) offered weak or no support for some nodes that were well-supported when more characters were included (as in the 390 taxon analysis). The known labyrinthulomycete sequences from cultivated strains, likely labyrinthulomycete environmental sequences from universal libraries, and all 68 of the 18S-F/LABY-Y amplicon sequences were consistently placed within 1 monophyletic lineage, concordant with the Labyrinthulea, within the heterokonts (nodes c and a in Fig. 1). Within the Labyrinthulea, there was strong support for the monophyly of the thraustochytrid phylogenetic group (third part of Fig. 1), containing most of the Thraustochytriidae and the recently described genera Aurantiochytrium, Schizochytrium (sensu stricto), Botryochytrium, Parietichytrium, Ulkenia (sensu stricto), and Sicyoidochytrium (Yokoyama \& Honda 2007, Yokoyama et al. 2007), and for a monophyletic group generally consistent with the Labyrinthulidae containing the genera Aplanochytrium and Labyrinthula (second part of Fig. 1). 
Table 3. Specificity of the 18S-F, LABY-A, and LABY-Y primers. For each group containing cultivated labyrinthulomycetes identified in Fig. 1, the number of species with 18S rDNA sequences that perfectly match each of the 3 primers is given as the first value. The second value shows the number of possible matches (18S rDNA sequences from that group that include the primer's target region). Lastly, the percentage of sequences in each group that matches each primer is given in parentheses. The total number of other eukaryote 18S rDNA sequences also perfectly matching each primer is shown in the last line. BLAST analysis was performed in June 2009. The values for $18 \mathrm{~S}-\mathrm{F}$ are likely substantial underestimates because the $18 \mathrm{~S}-\mathrm{F}$ site is at the very $5^{\prime}$ end of the $18 \mathrm{~S}$ rDNA, and is missing in many sequences. Among sequences that do contain the site there are many apparent sequencing errors (often missing bases) and uncertainties (degenerate bases), probably because the first part of sequencing reads tends to be poorly resolved. These issues prevent $18 \mathrm{~S}-\mathrm{F}$ from matching perfectly with many $18 \mathrm{~S}$ rDNA sequences in GenBank. See legend of Fig. 1 for abbreviations of genera. Y \& H: Yokoyama \& Honda 2007

\begin{tabular}{|lccc|}
\hline & $18 \mathrm{~S}-\mathrm{F}$ & LABY-A & LABY-Y \\
\hline Oblongichytrium $(Y \& H)$ & $0 / 3(0)$ & $15 / 15(100)$ & $11 / 13(85)$ \\
Labyrinthula & $0 / 5(0)$ & $15 / 17(88)$ & $4 / 14(29)$ \\
Aplanochytrium & $1 / 1(100)$ & $17 / 21(81)$ & $18 / 18(100)$ \\
Thraust pachydermum and QPX & $0 / 0$ & $3 / 3(100)$ & $2 / 3(67)$ \\
Parietichytrium & $0 / 0$ & $4 / 4(100)$ & $0 / 4(0)$ \\
Botryochytrium & $0 / 0$ & $2 / 2(100)$ & $0 / 2(0)$ \\
Thraust aureum & $0 / 0$ & $2 / 2(100)$ & $0 / 2(0)$ \\
Thraust kinnei & $1 / 1(100)$ & $2 / 2(100)$ & $0 / 2(0)$ \\
Thraust gaertnerium & $0 / 0$ & $1 / 1(100)$ & $0 / 1(0)$ \\
Schizochytrium & $0 / 1(0)$ & $7 / 7(100)$ & $0 / 7(0)$ \\
'Loides' haliotidis & $1 / 1(100)$ & $2 / 2(100)$ & $0 / 2(0)$ \\
Thraust striatum/motivum & $0 / 1(0)$ & $3 / 3(100)$ & $0 / 1(0)$ \\
Ulkenia & $0 / 0$ & $4 / 4(100)$ & $0 / 4(0)$ \\
Sicyoidochytrium & $0 / 5(0)$ & $5 / 5(100)$ & $0 / 5(0)$ \\
Thraust caudivorum & $0 / 0$ & $1 / 1(100)$ & $0 / 1(0)$ \\
Aurantiochytrium & $11 / 11(100)$ & $43 / 47(91)$ & $0 / 45(0)$ \\
Other Thraustochytrids & $0 / 0$ & $4 / 4(100)$ & $0 / 4(0)$ \\
Other eukaryotes & 2810 & 1936 & 0 \\
\hline
\end{tabular}

The thraustochytrid phylogenetic group was dominated by sequences from cultivated strains, which generally formed distinct groups corresponding to previously described genera and species (Fig. 1). The average sequence identity within these groups ranged from 88.9 to $99.6 \%$. Fifteen of the $18 \mathrm{~S}-\mathrm{F} / \mathrm{LABY}-\mathrm{Y}$ environmental amplicons also grouped with the thraustochytrids. Amplicon PJS101305_08 (FJ800627) was most similar to Thraustochytrium striatum AB022112 $(91.3 \%$ identical, node $\mathrm{r}$ in Fig. 1), while BBW042908_27 (FJ800589) was most similar to the abalone pathogen 'Labyrinthuloides' haliotidis U21338 (92.8\% identical, node q in Fig. 1; note that either the 'Loides' haliotidis isolate itself or the source of U21338 was probably misidentified, Leander \& Porter 2001). Amplicons LISW100206_08 (FJ800594) and PBS102907_61 (FJ800613) always grouped within the thraustochytrids, but not consistently with any other sequences. The remaining 11 amplicons, from 2 water samples, were $99 \%$ identical to each other. Together with 4 environmental sequences from 3 other studies (AY256273 and
AY256317 from the anoxic Cariaco Basin water column, Stoeck et al. 2003; DQ455713 from Barnegat Bay; EF539096 from a coastal Pacific sample), they formed a novel group, uTh1 (uncultivated thraustochytrid group 1), that was not closely related to any cultivated thraustochytrid, being less than $89 \%$ identical to 'Loides' haliotidis and less than $84 \%$ identical to Thraust kinnei (Fig. 1). Four additional environmental sequences from other studies also grouped within the thraustochytrids. A sequence from a mangrove leaf (DQ023610) was virtually identical to the 18S rDNA sequence of Aurantiochytrium (formerly Schizochytrium) mangrovei DQ100293. One sequence from an arctic sediment survey (EF100402; Stoeck et al. 2007) was nearly identical to Thraust kinnei, and 2 other sequences from the same study were most similar to each other and may represent another novel type of thraustochytrid (uTh2, Fig. 1). These later sequences, along with the cultivated strains H41, thel2, and 32 (DQ459556, DQ367051, and DQ367052), grouped consistently with Aurantiochytrium and may represent additional species of this recently described genus (Yokoyama \& Honda 2007) or related genera.

Twenty-one 18S-F/LABY-Y amplicons from 5 samples grouped with cultivated Aplanochytrium strains (some originally named Labyrinthuloides), with an overall average sequence identity for the group of $97.9 \%$ (node $\mathrm{j}$ in Fig. 1). Also grouping with the aplanochytrids were 1 isolate (PBS 07; FJ799799) cultivated from the PBS102907 sample (Table 5) and 15 environmental sequences from 6 other studies (Edgcomb et al. 2002, Stoeck et al. 2003, 2006, 2007, Massana et al. 2004a, Zuendorf et al. 2006). Three environmental sequences from sediment samples (Slapeta et al. 2005, Stoeck et al. 2007) grouped with the Labyrinthula, although no amplicons from the present study did. Four environmental sequences from 2 other studies (Luo et al. 2005, Stoeck et al. 2007) also grouped consistently with the larger Aplanochytrium and Labyrinthula group (node i in Fig. 1), and may represent novel members of the Labyrinthulidae, uLa8 (uncultivated labyrinthulid group 8).

One 18S-F/LABY-Y amplicon (LISS100206_04; FJ800652) as well as 6 isolates cultured from the PBS102907 sample (Table 4) grouped in Fig. 1 with the recently described genus Oblongichytrium (identified as Oblongichytrium [Y\&H]; Yokoyama \& Honda 2007), but this group did not have strong support in any other 
Table 4. Cultivation of labyrinthulomycete isolates from the PBS102907 sediment sample. Dilutions of 3 different subsamples were initially plated on solid 790 By+ medium, and isolates have since been maintained on the same or alternative media. HS: horse serum; ND: 18S rDNA from this culture has not been sequenced; $\mathrm{S}$ : solid medium (1.2\% agar plates); L: liquid medium (5 ml tubes); see 'Materials and methods' for other details of media composition

\begin{tabular}{|c|c|c|c|c|}
\hline Culture & $\begin{array}{l}\text { Subsample } \\
\text { and dilution }\end{array}$ & $\begin{array}{l}\text { Maintenance } \\
\text { medium }\end{array}$ & $\begin{array}{l}\text { Phylogenetic } \\
\text { position }\end{array}$ & $\begin{array}{l}\text { 18S rDNA } \\
\text { accession }\end{array}$ \\
\hline PBS01 & A, $10 \times$ & $790 \mathrm{By}+(\mathrm{S})$ & Unknown & ND \\
\hline PBS02 & A, $100 \times$ & 790 By+ or HS (S) & Oblongichytrium & FJ799796 \\
\hline PBS03 & $B, 10 \times$ & $790 \mathrm{By}+(\mathrm{S})$ & Oblongichytrium & GQ354272 \\
\hline PBS04 & $B, 10 \times$ & $790 \mathrm{By}+(\mathrm{L})$ & Oblongichytrium & FJ799797 \\
\hline PBS05 & $B, 100 \times$ & $790 \mathrm{By}+(\mathrm{L})$ & Oblongichytrium & FJ799794 \\
\hline PBS06 & $B, 100 \times$ & No longer viable & Oblongichytrium & FJ799798 \\
\hline PBS07 & $B, 100 \times$ & $\mathrm{HS}(\mathrm{S})$ & Aplanochytrium & FJ799799 \\
\hline PBS08 & C, $10 \times$ & No longer viable & Oblongichytrium & FJ799795 \\
\hline PBS09 & A, $10 \times$ & No longer viable & Unknown & ND \\
\hline PBS10 & A, $10 x$ & No longer viable & Unknown & ND \\
\hline PBS11 & $B, 10 \times$ & No longer viable & Unknown & ND \\
\hline
\end{tabular}

analysis. A sister group (identified as Oblongichytrium sp.?, node f in Fig. 1) comprising only environmental sequences, including 15 18S-F/LABY-Y amplicons from 3 sediment samples and 4 sequences from 3 other studies (Stoeck et al. 2003, 2007; the origin of EF526957 is unclear), might represent additional members of the genus Oblongichytrium. The combination of the 2 groups had slightly stronger statistical support (node e in Fig. 1), although PBS102405_39 (FJ800607), which is on a long branch in Fig. 1, did not belong to any of the Oblongichytrium groups that were wellsupported by the Bayesian analyses.

Fifteen 18S-F/LABY-Y amplicons formed 5 groups that were not closely related to cultivated labyrinthulomycetes: (1) uLa1 included 5 amplicons from 2 sediment samples that were similar to a sequence recovered from lobster larvae gut contents (AB219774), (2) uLa2 included 2 amplicons from 2 samples as well as 2 sequences from anoxic sediment (AB191423, AB191424; Takishita et al. 2005), (3) uLa3 included 5 amplicons from only 1 sample, (4) uLa4 included 1 amplicon that was $95.5 \%$ identical to arctic sediment sequence EF100352 (Stoeck et al. 2007), and (5) uLa5 included 2 amplicons from 1 water sample and a sequence from a Mediterranean Sea surface water sample (Massana et al. 2004a). PBS102907_29 (FJ800611), uLa2, uLa3, and uLa4 grouped weakly with Oblongichytrium (node $d$ in Fig. 1). Five sequences from other studies formed 2 additional groups not closely related to cultivated labyrinthulomycetes (uLa6 and uLa7; Massana et al. 2004b, Takishita et al. 2005, Behnke et al. 2006, Not et al. 2007, Stoeck et al. 2007). In addition, AY665006 (from the Sargasso Sea) consistently grouped among the Labyrinthulea but did not have a stable position.

\section{DISCUSSION}

The present study presents a phylogenetic analysis of all available (GenBank last searched in June 2009) 18S rDNA sequences from cultivated labyrinthulomycetes plus environmental 18S rDNA sequences that are related to cultivated labyrinthulomycetes. Overall, our phylogenetic analyses offered strong support for the monophyly of the cultivated labyrinthulomycetes, and included all 68 18SF/LABY-Y amplicons as well as 50 environmental sequences from other studies within the monophyletic group that was consistent with the Labyrinthulea (node $\mathrm{c}$ in Fig. 1). A group consisting entirely of environmental sequences belonging to MAST-7 and MAST-11 (Massana et al. 2004a,b) has been identified as Clade L by Cavalier-Smith \& Chao (2006), who suggested that this group has a sister relationship to the Labyrinthulea. Among our analyses, only the Bayesian tree constructed with the 390 taxon alignment showed strong support for the putative sister relationship between Labyrinthulea and Clade L (node b in Fig. 1), and none supported the placement of Labyrinthulea within the Bigyra with the Bicoecia and Opalazoa (CavalierSmith \& Chao 2006, Tsui et al. 2009). Differences between the present study and other studies in the relationships within the labyrinthulomycetes, and in the relationships between labyrinthulomycetes and other heterokonts, may be caused both by technical differences in alignments and phylogenetic reconstruction methods and by the broader taxon sampling within the labyrinthulomycetes used here. It is also possible that some of the environmental sequences from this or other studies are chimeric amplicons that we have not been able to identify as such, and that these chimeras disrupt some aspects of the topology. Continued improvement of taxon sampling may help to clarify the relationship between Labyrinthulea and other heterokonts. Cultivation of the organisms represented by Clade L as well as the groups of apparently uncultivated labyrinthulomycetes identified here would greatly help to define the limits and evolutionary history of the Labyrinthulea.

The historical difficulty of classifying labyrinthulomycetes in a phylogenetically coherent manner is illustrated here by the presence of isolates with a variety of genus names in groups of very similar 18S rDNA sequences, and by the appearance of genus names like Thraustochytrium and Schizochytrium throughout the Labyrinthulea (Fig. 1). Correcting this situation is the focus of active research (e.g. Leander et al. 2004, 
Cavalier-Smith \& Chao 2006, Yokoyama \& Honda 2007, Yokoyama et al. 2007, Tsui et al. 2009). In identifying groups of similar sequences in this analysis, we have relied on a combination of the genera named over the past few years by workers using molecular genetic, morphological, and physiological markers and on the strongly supported groups emerging from the phylogenetic analysis. The 18S rDNA sequence identity within the genera recently described by Yokoyama and coworkers (Yokoyama \& Honda 2007, Yokoyama et al. 2007) ranges from $94 \%$ for Parietichytrium to 99.4\% for Botryochytrium (Fig. 1). The groups of environmental sequences identified here as representing apparently novel labyrinthulomycetes fall into a similar range, from $93.3 \%$ average identity in uLa5 to $98.9 \%$ in uLa3. The high end of this range (near $99.5 \%$ identity) is similar to the variation reported among several Thraustochytrium caudivorum strains (Schärer et al. 2007), and can also arise from Taq polymerase error when amplifying a homogeneous template (J. Collier unpubl. data). A great deal more effort in studying the morphology, physiology, and ecology of these organisms will be required to determine whether the novel groups identified here are best described as new genera or species.

The Aplanochytrium group (node j in Fig. 1) was not supported in the analyses with 425 taxa because the Labyrinthula fell within the Aplanochytrium group in those trees. Aplanochytrids have been isolated from a variety of plant, algal, and animal substrates as well as sediment and seawater samples collected in polar, temperate, and tropical habitats (e.g. Leander et al. 2004, Damare \& Raghukumar 2006). In addition to the 18S-F/LABY-Y amplicon sequences recovered from Peconic Bay, Port Jefferson Harbor, and Long Island Sound sediment samples and a Peconic Bay seawater sample, 18S rDNA sequences very similar to cultivated aplanochytrids have been recovered in universal $18 \mathrm{~S}$ rDNA libraries constructed from a variety of sediment (including arctic and hydrothermal areas) and seawater samples (including normoxic Mediterranean surface seawater and the suboxic part of the Cariaco Basin water column) (Edgcomb et al. 2002, Stoeck et al. 2003, 2006, 2007, Massana et al. 2004a,b, Zuendorf et al. 2006). These results suggest that Aplanochytrium is a geographically widespread genus with restricted phylogenetic diversity. Damare \& Raghukumar (2006) recently suggested that aplanochytrids might be more abundant than thraustochytrids in open-ocean waters. The group of environmental sequences named uLa8 may represent either a novel species of Aplanochytrium or a novel related genus.

Labyrinthula spp. have been isolated largely from samples of living or dead plant or algal material, and 2 of the 3 Labyrinthula 18S rDNA sequences recovered in environmental libraries were from arctic samples where the supply of particulate organic matter was largely from decomposing red and brown seaweeds (Stoeck et al. 2007). The third was from a suboxic sediment sample (Slapeta et al. 2005). The diversity among cultivated Labyrinthula spp. (average sequence identity 88.1\%; Fig. 1) is much greater than among cultivated Aplanochytrium spp., suggesting that cultivated Labyrinthula represent several different species, or perhaps even different genera. Our analyses agree with previous work in suggesting that Aplanochytrium and Labyrinthula may be sister genera. However, while Labyrinthula has been consistently assigned to the Labyrinthulidae, Aplanochytrium is sometimes placed within the Thraustochytriidae (e.g. CavalierSmith \& Chao 2006, Tsui et al. 2009). Since Aplanochytrium does not belong to the monophyletic thraustochytrid phylogenetic group and does not possess an insertion in the 18S rDNA that is characteristic of the thraustochytrid phylogenetic group (Honda et al. 1999), it appears that the aplanochytrids would be better placed in the Labyrinthulidae or their own group (Leander \& Porter 2001, Leander et al. 2004).

Although the structure of the Oblongichytrium part of the tree was not well resolved, the sequences placed in the broader Oblongichytrium group in Fig. 1 are similar enough to each other (node d; 95.6\% average identity) to represent several species in the same genus. As suggested by Yokoyama \& Honda (2007), better understanding of the relationships among the organisms these sequences represent may require consideration of other characteristics in addition to $18 \mathrm{~S}$ rDNA. Because the genus Oblongichytrium is newly described and includes isolates previously named both Thraustochytrium and Schizochytrium, it would be difficult to draw generalities about its distribution from previous work. As in the case of Aplanochytrium, although the isolates recently placed in the genus Oblongichytrium have usually been associated with the Thraustochytriidae, they lack the thraustochytrid 18S rDNA signature insertion sequence (Honda et al. 1999) and do not fall within the thraustochytrid phylogenetic group, so they may be better placed in the Labyrinthulidae or a new family.

Relatively few 18S-F/LABY-Y amplicons (15 of 68) or environmental sequences from other studies (8 of 50) belonged to the thraustochytrid phylogenetic group. Interestingly, the majority of 18S-F/LABY-Y amplicons from our estuarine seawater samples belonged to thraustochytrids (13 of 17), while the vast majority of 18S-F/LABY-Y amplicons from our sediment samples did not (49 of 51). Taken at face value, these results may suggest a major difference in the ecology of these broad groups of labyrinthulomycetes. They may also suggest that thraustochytrids are less dominant in nat- 
ural communities than they are in culture collections. However, a bias against thraustochytrid sequences in our 18S-F/LABY-Y amplicon libraries could also reflect the specificity of the primer LABY-Y. When the primers LABY-A and LABY-Y were designed by Stokes et al. (2002), the labyrinthulomycete sequence database was much smaller, and it is now clear that LABY-A is too general (it will recognize other heterokonts) and LABY-Y is too specific (Fig. 2, Table 3). In particular, LABY-Y does not perfectly match Aurantiochytrium or Schizochytrium (sensu stricto) at residues near its $3^{\prime}$ end (Fig. 2). It also does not match some Labyrinthula. However, environmental sequences recovered in other studies, using different and more universal primer sets, show the same relative paucity of thraustochytrid sequences. We are currently developing modified versions of LABY-Y and other primers to better assess the diversity and abundance of labyrinthulomycetes.

It is striking that labyrinthulomycete sequences have been recovered from a number of $18 \mathrm{~S}$ rDNA surveys of protist diversity in suboxic and anoxic samples (see 'Results'). The possibility that these sequences represent viable organisms is supported by reports of the cultivation of labyrinthulomycetes from oxygendepleted habitats (Schneider 1969, Goldstein 1973, Cathrine \& Raghukumar 2009). Some isolates of Schizochytrium aggregatum have been reported to grow under a nitrogen atmosphere while others could not be grown anaerobically (Goldstein \& Belsky 1964, Schneider 1969). Interestingly, Schizochytrium ATCC 20888 uses an oxygen-independent polyketide synthase pathway for the synthesis of essential polyunsaturated fatty acids rather than the more common oxygen-requiring fatty acid synthase pathway (Qiu 2003, Lippmeier et al. 2009). Whether this reflects an adaptation to growth in oxygen-poor conditions remains to be explored. There is not yet enough information to determine whether the distribution of any particular labyrinthulomycete phylotype is determined by oxygen availability, and it is worth exploring whether lowoxygen conditions might support the cultivation of some of the novel labyrinthulomycetes found in environmental sequence surveys.

In conclusion, 18S rDNA sequences currently available from cultivated strains suggest that Labyrinthulea comprises a group of fairly distinct clusters of sequences that may represent at least distinct species, and perhaps distinct genera. Ten similarly distinct groups of environmental sequences identified in this study appear to represent novel, uncultivated species or genera of labyrinthulomycetes, and other unique sequences suggest that still greater diversity remains to be described. Sequences belonging to some of these novel groups have been detected in multiple studies in diverse habitats. Because these novel groups may rep- resent common and abundant but completely undescribed marine saprobes, it is important to gain insight into their physiological characteristics. Some freshly isolated labyrinthulomycetes are easily established as robust laboratory cultures, but many others fail to grow after one or a few transfers (J. Radway pers. obs.). We are investigating whether these ephemeral cultures may belong to the novel groups reported here and seeking to identify the factor(s) responsible for their failure to thrive in culture.

Acknowledgements. This work was supported by National Science Foundation grant OCE-0726702 to J.L.C. and by the generous support of E.C.M. by the Stony Brook University W. Burghardt Turner Fellowships, NSF- BRIDGE, and NSFAGEP programs. Sequencing was performed in the Molecular Evolution of Adaptation and Diversity (MEAD) lab, founded at Stony Brook University with funding from NSF (DBI0400829) to J.L.C. and J. True. The authors thank W. Lin for making possible the Bayesian phylogenetic analyses on the SoMAS 'everest' computer cluster. Special thanks to R. Cerrato, H. Bokuniewicz, G. Taylor, and the crew of RV 'SeaWolf' for providing sampling opportunities in Long Island Sound, Port Jefferson Harbor, and Bowery Bay, and to the crew of RV 'Paumanok' for supporting our sampling in Peconic Bay.

\section{LITERATURE CITED}

Amaral Zettler LA, Gomez F, Zettler E, Keenan BG, Amils R, Sogin ML (2002) Eukaryotic diversity in Spain's River of Fire. Nature 417:137

Baker KM, Gobler CJ, Collier JL (2009) Urease gene sequences from algae and heterotrophic bacteria in axenic and nonaxenic phytoplankton cultures. J Phycol 45: $625-634$

Behnke A, Bunge J, Barger K, Breiner HW, Alla V, Stoeck T (2006) Microeukaryote community patterns along an $\mathrm{O}_{2} / \mathrm{H}_{2} \mathrm{~S}$ gradient in a supersulfidic anoxic fjord (Framvaren, Norway). Appl Environ Microbiol 72:3626-3636

Bower SM (1987) Labyrinthuloides haliotidis n. sp. (Protozoa: Labyrinthomorpha), a pathogenic parasite of small juvenile abalone in a British Columbia mariculture facility. Can J Zool 65:1996-2007

> Cathrine SJ, Raghukumar C (2009) Anaerobic denitrification in fungi from the coastal marine sediments of Goa, India. Mycol Res 113:100-109

Cavalier-Smith T, Chao EEY (2006) Phylogeny and megasystematics of phagotrophic heterokonts (Kingdom Chromista). J Mol Evol 62:388-420

> Cavalier-Smith T, Allsopp MTEP, Chao EEY (1994) Thraustochytrids are chromists, not fungi: 18S rRNA signatures of Heterokonta. Philos Trans R Soc Lond B Biol Sci 346: 387-397

Countway PD, Gast RJ, Savai P, Caron DA (2005) Protistan diversity estimates based on 18S rDNA from seawater incubations in the western North Atlantic. J Eukaryot Microbiol 52:95-106

Damare V, Raghukumar S (2006) Morphology and physiology of the marine straminipilan fungi, the aplanochytrids isolated from the equatorial Indian Ocean. Indian J Mar Sci 35:326-340

Dick MW (2001) Straminipilous fungi: systematics of the peronosporomycetes including accounts of the marine 
straminipilous protists, the plasmodiophorids and similar organisms. Kluwer Academic Publishers, Dordrecht

Edgcomb VP, Kysela DT, Teske A, de Vera Gomez A, Sogin ML (2002) Benthic eukaryotic diversity in the Guaymas Basin hydrothermal vent environment. Proc Natl Acad Sci USA 99:7658-7662

$>$ Goldstein S (1973) Zoosporic marine fungi (Thraustochytriaceae and Dermocystidiaceae). Annu Rev Microbiol 27: $13-25$

Goldstein S, Belsky M (1964) Axenic culture studies of a new marine phycomycete possessing an unusual type of asexual reproduction. Am J Bot 51:72-78

Hall TA (1999) BioEdit: a user-friendly biological sequence alignment editor and analysis program for Windows 95/98/NT. Nucleic Acids Symp Ser 41:95-98

> Honda D, Yokochi T, Nakahara T, Raghukumar S, Nakagiri A, Schaumann K, Higashihara T (1999) Molecular phylogeny of labyrinthulids and thraustochytrids based on the sequencing of $18 \mathrm{~S}$ ribosomal RNA gene. J Eukaryot Microbiol 46:637-647

- Huber T, Faulkner G, Hugenholtz P (2004) Bellerophon: a program to detect chimeric sequences in multiple sequence alignments. Bioinformatics 20:2317-2319

Kumar S, Tamura K, Nei M (2004) MEGA3: integrated software for molecular evolutionary genetics analysis and sequence alignment. Brief Bioinform 5:150-163

Leander CA, Porter D (2000) Redefining the genus Aplanochytrium (Phylum Labyrinthulomycota). Mycotaxon 76: 439-444

> Leander CA, Porter D (2001) The Labyrinthulomycota is comprised of three distinct lineages. Mycologia 93:459-464

> Leander CA, Porter D, Leander BS (2004) Comparative morphology and molecular phylogeny of aplanochytrids (Labyrinthulomycota). Eur J Protistol 40:317-328

Lippmeier JC, Crawford KS, Owen CB, Rivas AA, Metz JG, Apt KE (2009) Characterization of both polyunsaturated fatty acid biosynthetic pathways in Schizochytrium sp. Lipids 44:621-630

> López-García P, Rodríguez-Valera F, Pedrós-Alió C, Moreira D (2001) Unexpected diversity of small eukaryotes in deep-sea Antarctic plankton. Nature 409:603-607

Luo Q, Krumholz LR, Najar FZ, Peacock AD, Roe BA, White DC, Elshahed MS (2005) Diversity of the microeukaryotic community in sulfide-rich Zodletone Spring (Oklahoma). Appl Environ Microbiol 71:6175-6184

> Massana R, Balague V, Guillou L, Pedrós-Alió C (2004a) Picoeukaryote diversity in an oligotrophic coastal site studied by molecular and culturing approaches. FEMS Microbiol Ecol 50:231-243

Massana R, Castresana J, Balague V, Guillou L and others (2004b) Phylogenetic and ecological analysis of novel marine stramenopiles. Appl Environ Microbiol 70:3528-3534

Medlin LK, Elwood HJ, Stickel S, Sogin ML (1988) The characterization of enzymatically amplified eukaryotic 16Slike rRNA-coding regions. Gene 71:491-499

> Muehlstein LK, Porter D, Short FT (1988) Labyrinthula sp., a marine slime mold producing the symptoms of wasting disease in eelgrass, Zostera marina. Mar Biol 99:465-472

Not F, Gausling R, Azam F, Heidelberg JF, Worden AZ (2007) Vertical distribution of picoeukaryotic diversity in the Sargasso Sea. Environ Microbiol 9:1233-1252

Porter D (1990) Phylum Labyrinthulomycota. In: Margulis L, Corliss JO, Meklonian M, Chapman DJ (eds) Handbook of Protoctista. Jones and Bartlett Publishers, Boston, MA, p 388-398

Qian H, Liu Q, Allam B, Collier JL (2007) Molecular genetic variation within and among isolates of QPX (Thraustochytriidae), a parasite of the hard clam Mercenaria mercenaria. Dis Aquat Org 77:159-168

Qiu X (2003) Biosynthesis of docosahexaenoic acid (DHA, 22:6-4,7,10,13,16,19): two distinct pathways. Prostaglandins Leukot Essent Fatty Acids 68:181-186

Raghukumar S (2002) Ecology of the marine protists, the Labyrinthulomycetes (Thraustochytrids and Labyrinthulids). Eur J Protistol 38:127-145

Raghukumar S, Ramaiah N, Raghukumar C (2001) Dynamics of thraustochytrid protists in the water column of the Arabian Sea. Aquat Microb Ecol 24:175-186

Richards TA, Vepritskiy AA, Gouliamova DE, NierzwickiBauer SA (2005) The molecular diversity of freshwater picoeukaryotes from an oligotrophic lake reveals diverse, distinctive and globally dispersed lineages. Environ Microbiol 7:1413-1425

Riemann F, Schrage M (1983) On a mass occurrence of a thraustochytrid protist (fungi or rhizopodan protozoa) in an Antarctic anaerobic marine sediment. Veröff Inst Meeresforsch Bremerh 19:191-202

Ronquist F, Huelsenbeck JP (2003) MRBAYES 3: Bayesian phylogenetic inference under mixed models. Bioinformatics 19:1572-1574

Schärer L, Knoflach D, Vizoso DB, Rieger G, Peintner U (2007) Thraustochytrids as novel parasitic protists of marine freeliving flatworms: Thraustochytrium caudivorum sp. nov. parasitizes Macrostomum lignano. Mar Biol 152:1095-1104

Schneider J (1969) Zur Taxonomie, Verbreitung und Ökologie einiger mariner Phycomyceten. Kieler Meeresforsch 25:316-327

Slapeta J, Moreira D, López-García P (2005) The extent of protist diversity: insights from molecular ecology of freshwater eukaryotes. Proc R Soc Lond B Biol Sci 272: 2073-2081

> Stamatakis A, Hoover P, Rougemont J (2008) A rapid bootstrap algorithm for the RAxML web-servers. Syst Biol 57: 758-771

Stoeck T, Taylor GT, Epstein SS (2003) Novel eukaryotes from the permanently anoxic Cariaco Basin (Caribbean Sea). Appl Environ Microbiol 69:5656-5663

Stoeck T, Hayward B, Taylor GT, Varela R, Epstein SS (2006) A multiple PCR-primer approach to access the microeukaryote diversity in environmental samples. Protist 157:31-43

Stoeck T, Kasper J, Bunge J, Leslin C, Ilyin V, Epstein S (2007) Protistan diversity in the Arctic: a case of paleoclimate shaping modern biodiversity? PLoS One 2:e728

Stokes NA, Calvo LMR, Reece KS, Burreson EM (2002) Molecular diagnostics, field validation, and phylogenetic analysis of Quahog Parasite Unknown (QPX), a pathogen of the hard clam Mercenaria mercenaria. Dis Aquat Org 52:233-247

Takishita K, Miyake H, Kawato M, Maruyama T (2005) Genetic diversity of microbial eukaryotes in anoxic sediment around fumaroles on a submarine caldera floor based on the small-subunit rDNA phylogeny. Extremophiles 9:185-196

Tillett D, Neilan BA (2000) Xanthogenate nucleic acid isolation from cultured and environmental cyanobacteria. J Phycol 36:251-258

> Tsui CKM, Marshall W, Yokoyama R, Honda D and others (2009) Labyrinthulomycetes phylogeny and its implications for the evolutionary loss of chloroplasts and gain of ectoplasmic gliding. Mol Phylogenet Evol 50:129-140

> Whyte SK, Cawthorn RJ, McGladdery SE (1994) QPX (Quahaug Parasite X), a pathogen of northern quahaug Merce- 
naria mercenaria from the Gulf of St. Lawrence, Canada. Dis Aquat Org 19:129-136

Wuyts J, Perriere G, Van de Peer Y (2004) The European ribosomal RNA database. Nucleic Acids Res 32:D101-D103

Yokoyama R, Honda D (2007) Taxonomic rearrangement of the genus Schizochytrium sensu lato based on morphology, chemotaxonomic characteristics, and 18S rRNA gene phylogeny (Thraustochytriaceae, Labyrinthulomycetes): emendation for Schizochytrium and erection of Aurantiochytrium and Oblongichytrium gen. nov. Mycoscience 48:199-211

Editorial responsibility: Daniel Vaulot, Roscoff, France
Yokoyama R, Salleh B, Honda D (2007) Taxonomic rearrangement of the genus Ulkenia sensu lato based on morphology, chemotaxonomical characteristics, and 18S rRNA gene phylogeny (Thraustochytriaceae, Labyrinthulomycetes): emendation for Ulkenia and erection of Botryochytrium, Parietichytrium, and Sicyoidochytrium gen. nov. Mycoscience 48:329-341

Zuendorf A, Bunge J, Behnke A, Barger KJA, Stoeck T (2006) Diversity estimates of microeukaryotes below the chemocline of the anoxic Mariager Fjord, Denmark. FEMS Microbiol Ecol 58:476-491

Submitted: March 11, 2009; Accepted: July 27, 2009 Proofs received from author(s): December 2, 2009 